\title{
An evaluation of the Coulter model $\mathrm{S}$
}

\author{
D. F. BARNARD, A. B. CARTER, P. J. CROSLAND-TAYLOR, \\ AND J. W. STEWART
}

From the Bland-Sutton Institute of Pathology, The Middlesex Hospital, London

This report is concerned with the performance of the fully automatic counter Coulter model $S$. The apparatus consists of four units two of which, the electrical power and the vacuum and air pressure units, may be placed under the bench. The counter itself and its printout must be sited side by side on the bench (Fig. 1). Apart from what can be seen on the front, the cabinet conceals a mass of electrical, hydraulic, and pneumatic apparatus some of which is shown in Figure 2. To operate the counter is simple. The sampling tube A (Fig. 3) is placed in the blood container and the bar pushed. As soon as the light behind the bar changes to red, the sample is removed, the form fed into the printout and some 40 seconds later, after some hissing and gurgling, the printer thumps out the form with the results of the haemoglobin, red cell count, white cell count, packed cell volume, mean corpuscular volume, mean corpuscular haemoglobin concentration, and mean corpuscular haemoglobin.

The apparatus aspirates 1.2 to $1.3 \mathrm{ml}$ of blood, most of which is used to flush out the previous

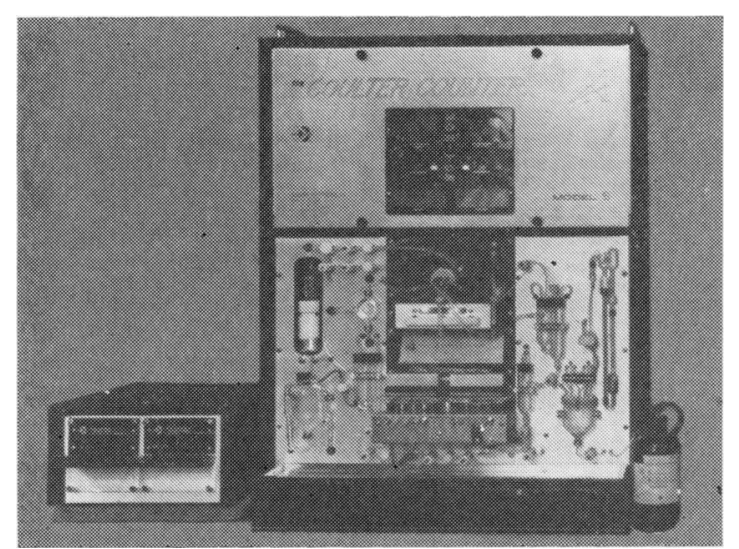

FIG. 1.

FIG. 1. The Coulter model $S$ counter with the printout

pump units are below the bench and not shown. hydraulic metering apparatus. All can easily be withdrawn and replaced in the event of a failure. sample, only $44.7 \mathrm{cmm}$ being used for the measure? ments. The machine can count a diluted capillary blood sample fed into a second sample tube $\mathbf{B}^{\omega}$ (Fig. 3). The dilution required is $44.7 \mathrm{cmm}$ in $10 \mathrm{mh}$ but as it will accept volumes ranging from 9 to $11 \mathrm{ml}$ $40 \mathrm{cmm}$ can be diluted in $9 \mathrm{ml}$ buffered saline and this results in an undercount of only $0.5 \%$. The counting rate is theoretically 180 per hour as the machine is capable of accepting a new sample every 20 seconds In practice, feeding in samples and forms takes az little time and the fastest I have achieved, working alone, is 121 counts in 50 minutes, a rate of $145_{0}^{\circ}$ per hour.

The forms used at present are purchased fromo Coulter Electronics but we are designing a request form which will also be a report form, and as all theo results will be on the left hand side, it is suitable for serial reporting (Fig. 4). The size of the form and the initial seven results are dictated by the printout of the apparatus. (An interface is now available which ${ }^{3}$ will punch the results on punch tape as an additiona or alternative method of recording.)

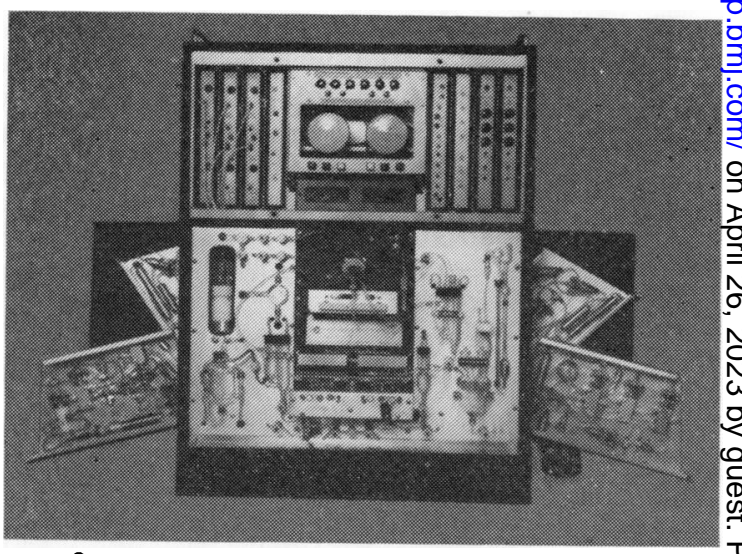

FIG. 2 . 


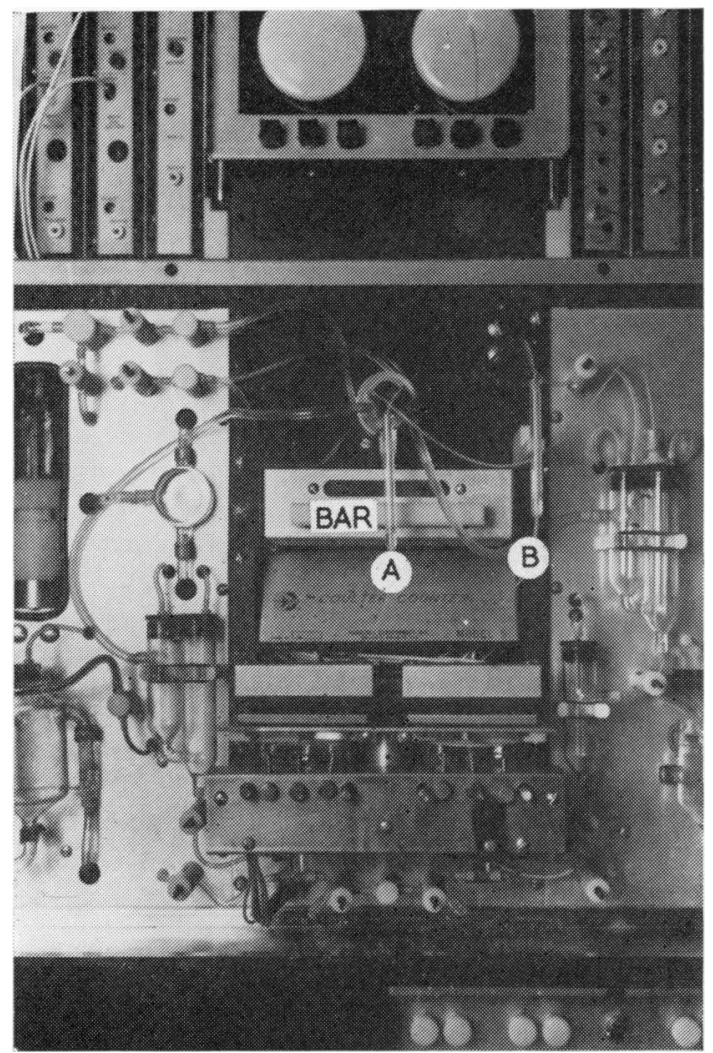

FIG. 3. A close-up view of the sampling tubes and operating bar. ' $A$ ' is for whole blood samples, ' $B$ ' for diluted blood samples, obtained, eg, from capillary blood. The operating bar is pushed to aspirate the sample and behind it is the light which shows green when the apparatus is ready to accept a further sample.

FIG. 4. Five of the result sheets mounted on a backing card as in the patient's notes. The results mounted are every twentieth result of the 100 counts done on the same venous blood sample to determine reproducibility.

FIG. 3.

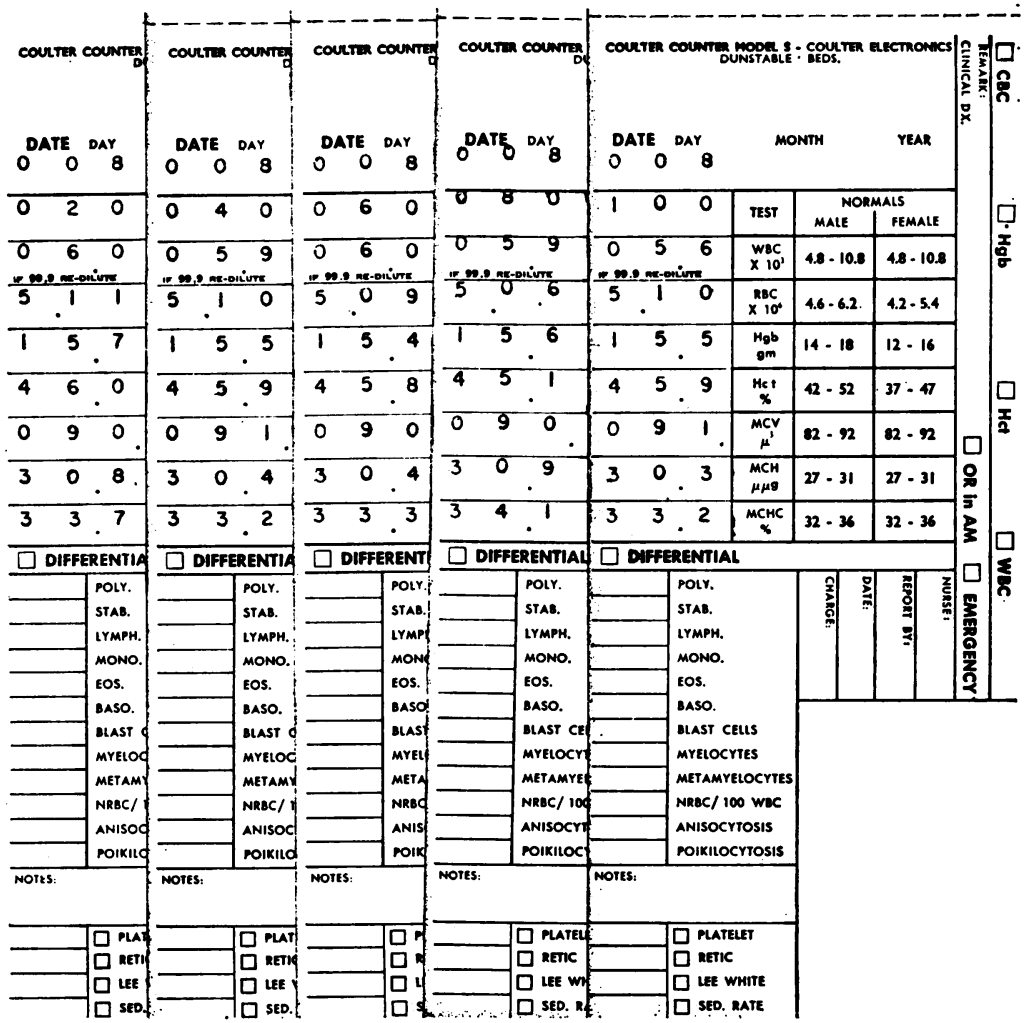

FIG. 4 . 
The counts are done by the usual Coulter principle of drawing a diluted sample through a small aperture through which an electrical current is passing. The momentary rise in resistance as a particle passes through is recorded and sized. There are six apertures, three for red cells and three for leucocytes. The count from each aperture is recorded separately, corrected for coincidence, the three results averaged and then printed. If any aperture records a count differing by more than 3 SD from the others that count is not used for the average and a red light shows under the oscilloscope display of the aperture concerned so that the operator can inspect it and take remedial action if required. The haemoglobin is measured by an optical density method, the pigment having already been converted to cyanmethaemoglobin. As the erythrocytes are being counted, the mean corpuscular volume is measured by summating the height of the pulses and dividing by the number of red cells. The packed cell volume is computed from this figure multiplied by the red cell count. The mean corpuscular haemoglobin (MCH) and mean corpuscular haemoglobin concentration (MCHC) are computed in the usual way from the haemoglobin and red cell count and haemoglobin and packed cell volume respectively.

For all the tests reported here we have used the buffered saline recommended by the manufacturers and bought from them. This is rather expensive, $£ 6$ for 5 gallons. At present the lysing agent used to destroy the red cells and convert the haemoglobin to cyanmethaemoglobin in 10 seconds must be bought from the manufacturers and is very expensive at $£ 6$ per $500 \mathrm{ml}$. Using these materials each count costs approximately $5 \cdot 77 \mathrm{~d}$. The saline has been most satisfactory, giving blanks of 0 to $0.01 \mathrm{M}$ per $\mathrm{cmm}$ in the red count. Not all batches of lysing agent have been satisfactory, some giving counts of 600 or more per cmm, but this has improved and

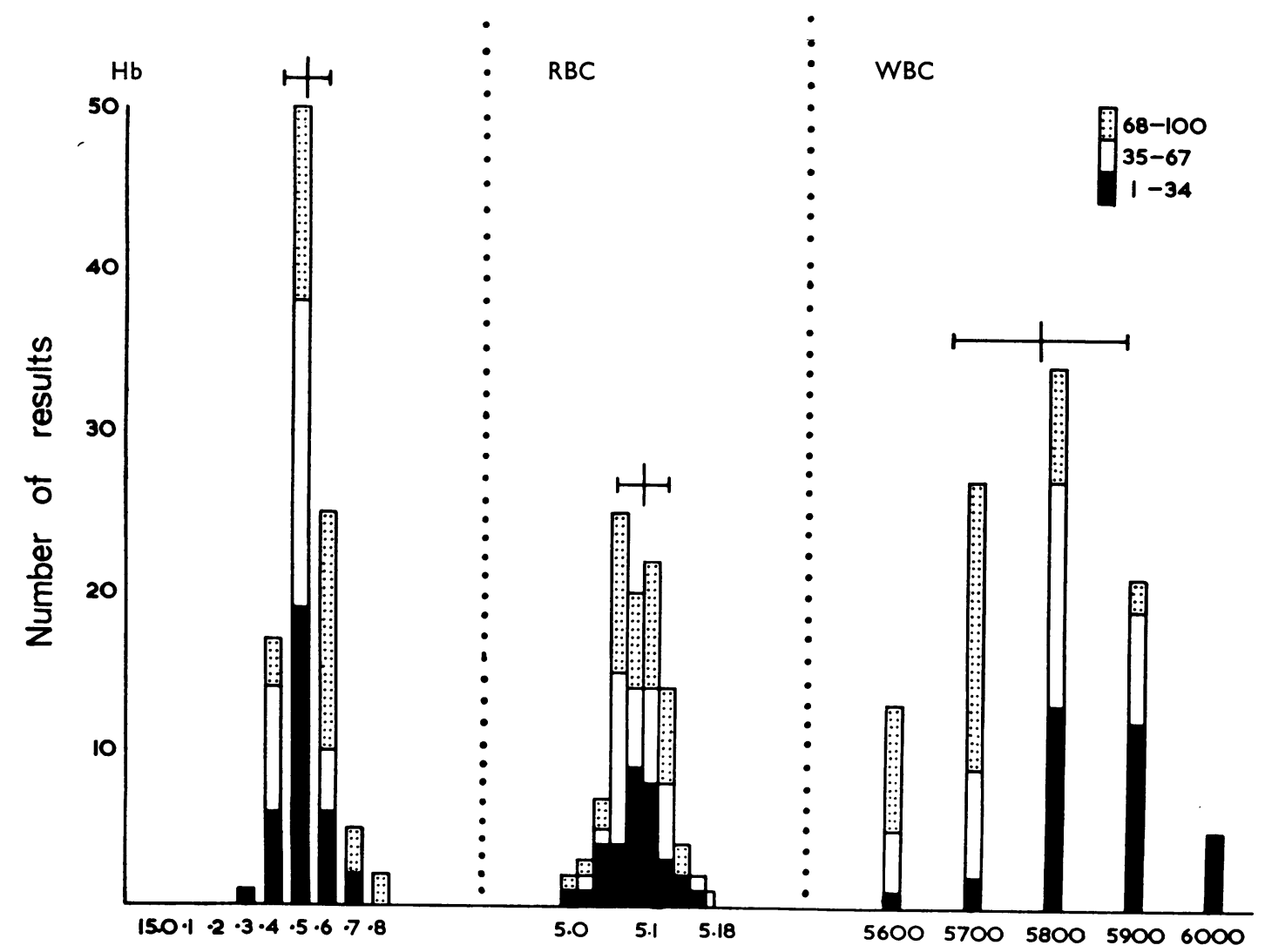

FIG. 5. The results of the haemoglobin $(H b)$, red cell $(R B C)$, and white cell count $(W B C)$ in the reproducibility trial in which 100 counts were done on the same sample of venous blood. Mean: Hb, 15.522 $\mathrm{g} / 100 \mathrm{ml} ; \mathrm{RBC}, 5.089 \mathrm{~m} / \mathrm{cmm}$; $W B C, 5,778 / \mathrm{cmm}$. SD: $\mathrm{Hb}, 0.0843 \mathrm{~g} / 100 \mathrm{ml} ; \mathrm{RBC}, 0.039 \mathrm{~m} / \mathrm{cmm} ; \mathrm{WBC}, 107.4 \mathrm{cmm}$. 
now we have blanks of between 100 and 200 per $\mathrm{cmm}$. It is important to have low and constant counts in the diluents as the results are printed directly onto the report form. It must be appreciated that the apparatus is essentially a comparator, expressing results in proportion to the original calibration, and does not count a metered volume of fluid. Once it has been calibrated it has remained stable for some weeks and does not require daily adjustment, nor does it appear necessary to count the same blood sample at intervals throughout the day.

To determine the reproducibility and accuracy with which the machine can count any given blood sample, 100 counts were done on one sample drawn from a single donor. Figure 5shows the haemoglobin, erythrocyte and leucocyte counts, their ranges, means, and standard deviations of that example. The distribution curve appears to be normal and the results obtained at the beginning, middle, and end of the runs are shown. There is no significant difference between the groups of results at any time during these 100 counts. The coefficient of variation of the haemoglobin and red cell count was just over $\pm 0.5 \%$ but that of the leucocytes $1 \cdot 8 \%$. Figure 6 shows the results for MCV, PCV, MCH, and MCHC, and the coefficient of variation which is $\pm 1 \%$ or less. The mean results from the counter were all within $1 \%$ of values determined by other methods for $\mathrm{Hb}$,

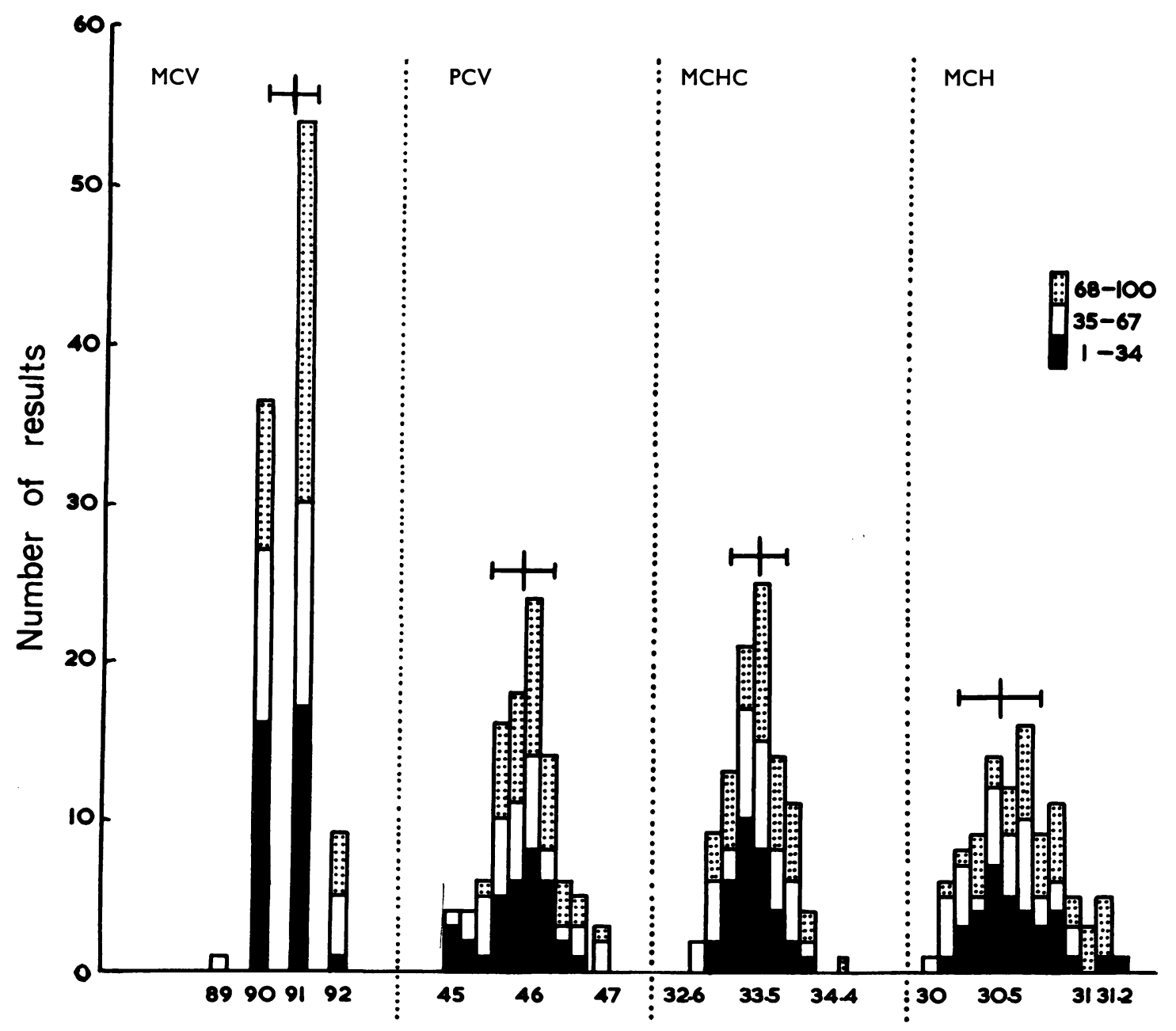

FIG. 6. The results of the mean corpuscular volume (MCV), packed cell volume (PVC), mean corpuscular haemoglobin concentration (MCHC), and mean corpuscular haemoglobin $(\mathrm{MCH})$ on 100 counts of the same blood sample as in

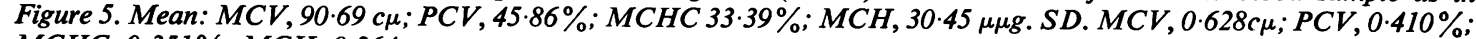
$M C H C, 0 \cdot 351 \% ; M C H, 0 \cdot 264 \mu \mu g$. 
RBC, WBC, and PCV except for WBC which was within $2 \%$.

The reproducibility of the results with the machine for diluted samples was tested similarly and the results are shown in Figures 7 and 8 . Only 33 counts on the same sample were done in this experiment but the range and variation between the results is of the same order as that for whole blood samples, the coefficient of variation for all being again $\pm 1 \%$ except for the leucocytes which was $2.0 \%$.

It is important to know if the results are linear throughout the whole range. For this purpose a polycythaemic blood was progressively diluted using buffered saline. Figure 9 shows the haemoglobin and PCV. It can be seen that results are linear from 20.0 to $1.0 \mathrm{~g}$ for the haemoglobin and from $74 \%$ to $3.7 \%$ for the PCV. Figure 10 shows the red and white cell counts. The red cells are linear from $10 \cdot 0$ to $0.5 \mathrm{M}$ per $\mathrm{cmm}$ and the leucocytes from 6,200 to 310 per $\mathrm{cmm}$. The linearity of the leucocyte count at higher levels was tested by progressively diluting a leukaemic blood and the result is shown in Figure 11. It is linear from 50,000 to 5,000 per $\mathrm{cmm}$. It is not possible to count samples when the leucocyte count exceeds 53,000 as the machine has a built-in cutoff which ensures that it does not print results above this level, the reason possibly connected with the fact that the sample in which the haemoglobin is measured is also used for the white cell count. The leucocytes must therefore be preserved and large numbers of these could cause opacity and result in erroneous haemoglobin values. If this is the position then the cutoff has probably been set too

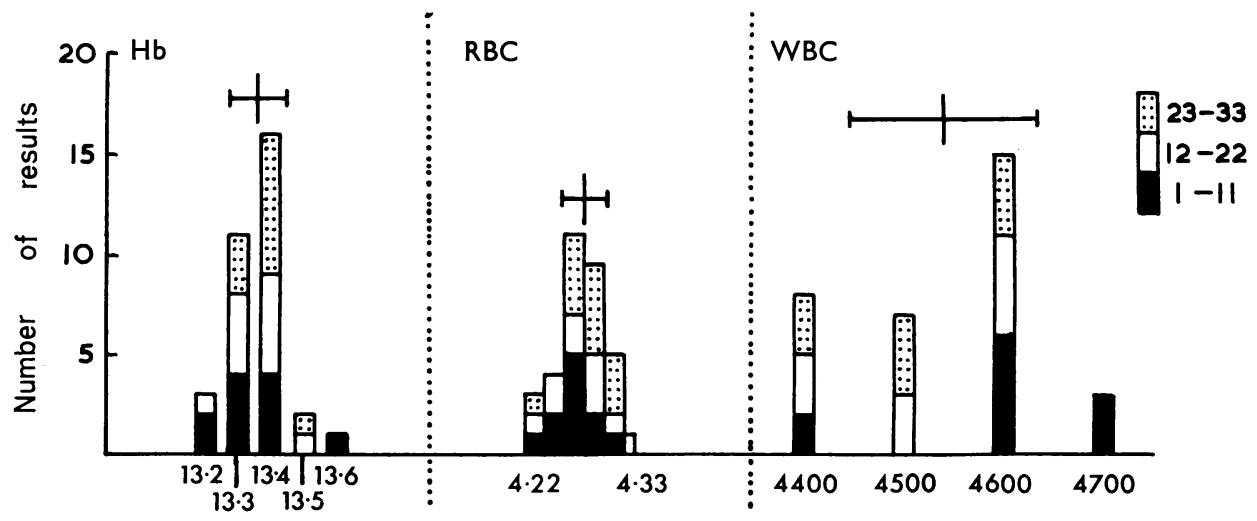

FIG. 7. The results of the haemoglobin $(H b)$, red cell count $(R B C)$, and white cell count $(W B C)$ of 33 counts of the same diluted blood sample to determine the reproducibility of the apparatus for handling samples obtained from capillary blood. Mean: Hb, 13.357g/100 ml; RBC, $4.280 \mathrm{~m} / \mathrm{cmm} ; \mathrm{WBC}, 4,539 / \mathrm{cmm}$. SD: Hb, $0.0836 \mathrm{~g} / 100 \mathrm{ml} ; \mathrm{RBC}, 0.0235$ $\mathrm{m} / \mathrm{cmm} ; \mathrm{WBC}, 95 \cdot 3 / \mathrm{cmm}$.

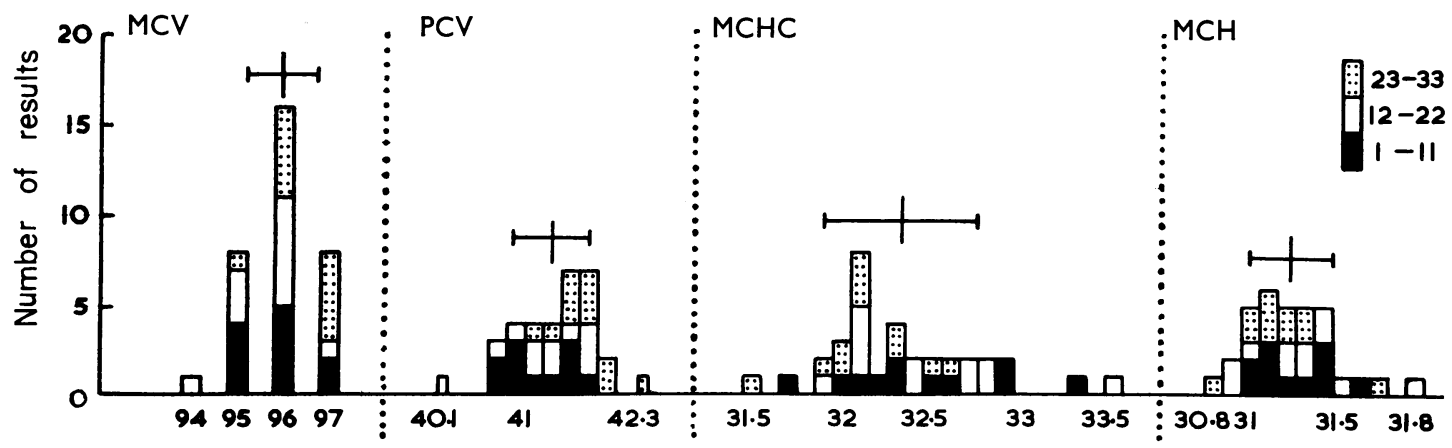

IIG. 8. The results of the mean corpuscular volume (MCV), packed cell volume (PCV), mean corpuscular haemoglobin concentration $(\mathrm{MCHC})$, and mean corpuscular haemoglobin $(\mathrm{MCH})$ of 33 counts of the same diluted blood sample

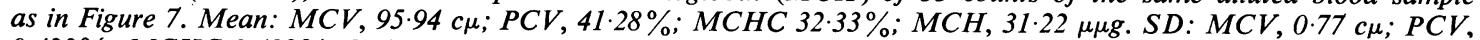
$0.423 \%: M C H C 0.422 \% ; M C H, 0.233 \mu \mu g$. 


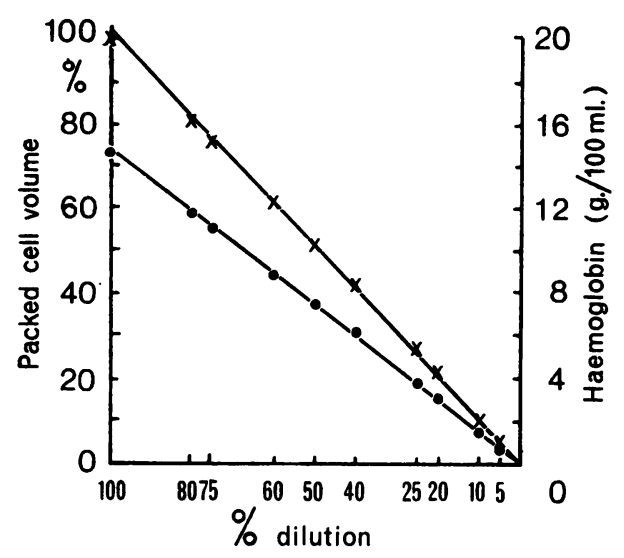

FIG. 9. The results of the haemoglobin (upper line) and packed cell volume (lower line) in the experiment to determine linearity. For this experiment a polycythaemic blood sample was progressively diluted by a known amount.

high because the haemoglobin value given by the apparatus is significantly raised when the leucocyte count is 50,000 per $\mathrm{cmm}$, the error being worse in myelocytic than in chronic lymphocytic leukaemia due no doubt to the larger size (and greater opacity) of the myelocyte. Leucocyte counts up to 20,000 do not appear to cause any significant error but counts above this value cause the haemoglobin to be read too high, the error increasing as the leucocyte count becomes higher. It would be better to set the level at which the machine did not record a leucocyte count at 20,000 per $\mathrm{cmm}$. High leucocyte counts also affect the MCV, which is computed from the size of both leucocytes and red cells when the red

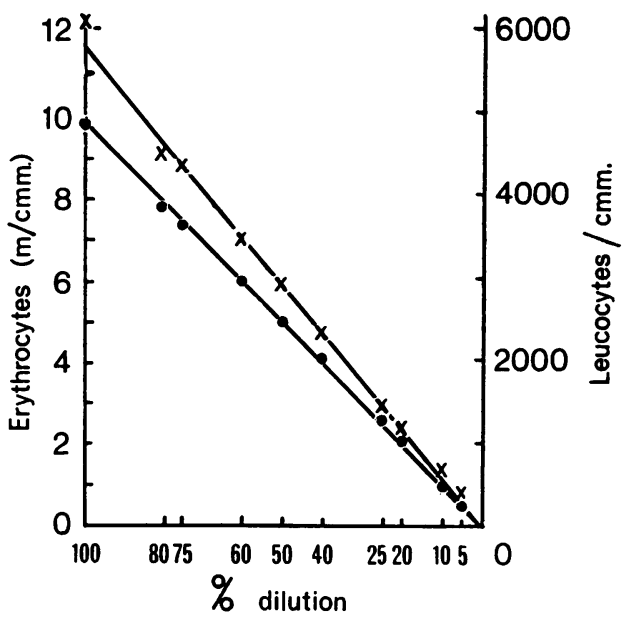

FIG. 10. The results of the red cell count (lower line) and white cell count (upper line) in the experiment to determine linearity obtained at the same time as the results in Figure 9.

cell count is done, resulting in too high a value for the PCV. At haemoglobin levels of about $7 \mathrm{~g}$ the MCV and PCV are detectably too high when the leucocyte count is 25,000 per $\mathrm{cmm}$ and constitutes a further reason for reducing the level of the cutoff of the machine for leucocyte counts. There is no difficulty with low leucocyte counts, the lowest successfully counted being 200 per $\mathrm{cmm}$.

The 'carryover' from one specimen to the next has been determined by counting a single sample of blood 10 times and then alternately counting buffered saline and the same blood sample 10 times. In this way, the amount by which a low count will be raised by a preceding high count and
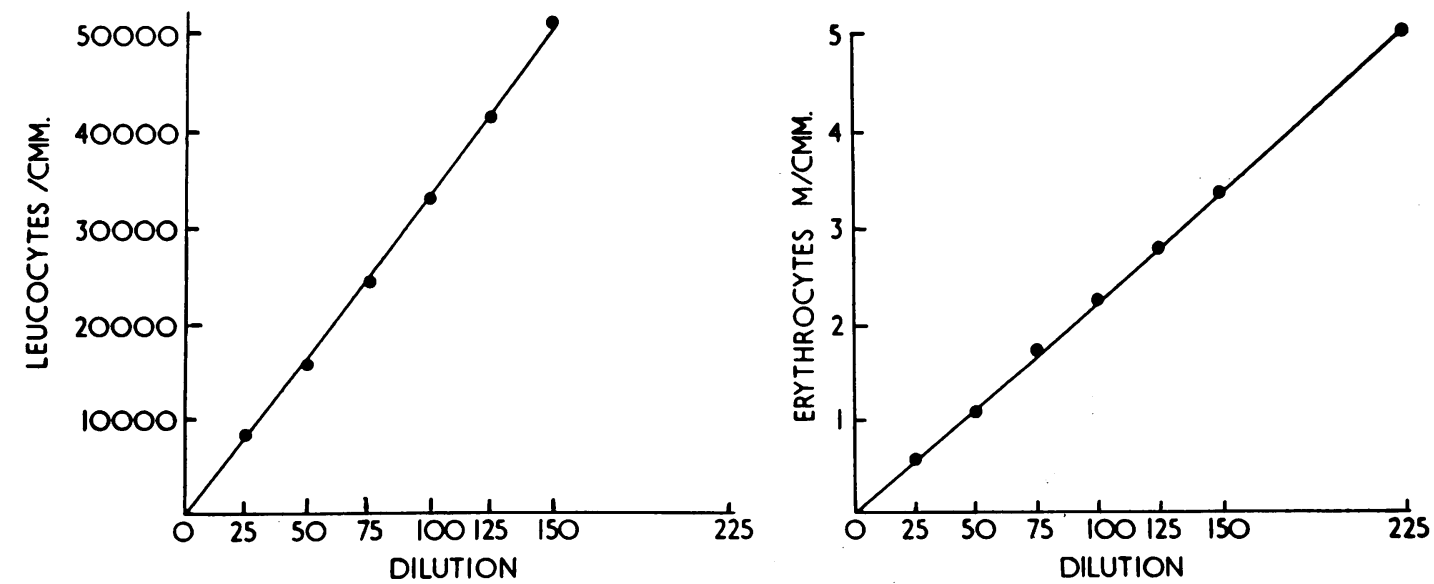

FIG. 11. The results of the white and red cell counts obtained when a leukaemic blood was progressively diluted by a known amount. The experiment was performed to determine linearity at higher leucocyte counts than in Figure 10. 
vice versa can be determined. The results for the WBC, RBC, Hb, and PCV are shown in Table I, which shows that the effect in both directions is of the order of 2 to $3 \%$. Using saline with almost zero counts constitutes the most severe test possible and maximizes the carryover, which is detectable only in the first count following saline and therefore only

\begin{tabular}{|c|c|c|c|c|}
\hline & \multicolumn{2}{|c|}{$\begin{array}{l}\text { TABLE I } \\
\text { CARRYOVER }\end{array}$} & \multirow[b]{2}{*}{$H b$} & \multirow[b]{2}{*}{$P C V$} \\
\hline & $W B C$ & $R B C$ & & \\
\hline Blank & 100 & $0.01 \mathrm{M}$ & 000 & $0 \cdot 1$ \\
\hline Average 9 bloods & 3,056 & $3 \cdot 261$ & $10 \cdot 08$ & 31.9 \\
\hline $\begin{array}{l}\text { Average } 9 \text { bloods } \\
\text { each following blank } \\
\text { average } 10\end{array}$ & 2,930 & $3 \cdot 193$ & 9.9 & $31 \cdot 08$ \\
\hline $\begin{array}{l}\text { Average } 10 \text { bloods } \\
\text { taking blanks too } \\
\text { low by }\end{array}$ & 86 & 0.068 & $0 \cdot 18$ & $0 \cdot 82$ \\
\hline Percentage low & $2 \cdot 7 \%$ & $2 \cdot 1 \%$ & $1 \cdot 8 \%$ & $2 \cdot 6 \%$ \\
\hline $\begin{array}{l}\text { Blank up by } \\
\text { (mean of } 10 \\
\text { following blood) }\end{array}$ & 150 & 0.055 & $0 \cdot 1$ & 0.6 \\
\hline Percentage raised & $3 \cdot 1$ & 1.9 & 1 & $2 \cdot 0$ \\
\hline
\end{tabular}

nine of the 10 counts in the blood sample were used, the first, which was lower by almost $2.5 \%$, being discarded. In practice, this can be ignored for most samples, as only those counts following very high leucocyte or erythrocytic counts need be repeated.

The tolerance of the apparatus to variation in the mains voltage was also tested by fitting a variac transformer on the mains lead and simply adjusting the voltage at which power was delivered to the counter. The results are shown in Table II. The

TABLE II

\begin{tabular}{lccccc}
\multicolumn{5}{c}{ EFFECT OF VOLTAGE VARIATION } \\
Voltage & $W B C$ & $R B C$ & $H b$ & $P C V$ & $M C V$ \\
\hline 180 & 5,800 & $412 \mathrm{M}$ & $14 \cdot 4$ & $45 \cdot 1$ & 109 \\
200 & 5,600 & $415 \mathrm{M}$ & $14 \cdot 2$ & $45 \cdot 7$ & 109 \\
220 & 5,500 & $414 \mathrm{M}$ & $14 \cdot 1$ & $45 \cdot 5$ & 110 \\
240 & 5,500 & $412 \mathrm{M}$ & $14 \cdot 2$ & $45 \cdot 5$ & 109 \\
260 & 5,400 & $414 \mathrm{M}$ & $14 \cdot 2$ & $45 \cdot 4$ & 110
\end{tabular}

mains voltage in our laboratory is 230 and it was varied between 180 and 260 , but no higher since this is the highest voltage allowed by the manufacturers. The counts shown are the means of 10, all done on the same blood. The leucocyte count appears to fall but we do not believe this is so; it merely reflects a fall in the particle count in the lysing agent, or lines from it, which on that day was rather high at the start of the experiment but which sub- sequently fell. This was due to inadequate flushing of the lines.

The bloods from patients suffering from various haematological disorders such as the haemolytic anaemias, hereditary (thalassaemia) and acquired, megaloblastic and hypochromic anaemias, nonleukaemic leukaemias, myelomas, polycythaemias, and cord bloods, have been counted in the apparatus and all seem to be counted satisfactorily. The results of the haemoglobin, red and white cell counts, and packed cell volume determinations on the blood specimens for the first 100 patients which were done in parallel by the Coulter $\mathrm{S}$ and by 'manual' methods, which include the use of photoelectric colorimeters, the Coulter counter model 'A', a microhaematocrit centrifuge, and some results checked visually in addition, using a haemocytometer, are shown in Figure 12. The combined results for the 100 bloods have been added up and the ratio is close to 1.0 for all, the leucocyte count deviating slightly more than the others, reflecting the trouble we had with leucocyte blanks (Table III). The counts were done

\section{TABLE III}

TOTALS FOR 100 CONSECUTIVE COUNTS ON DIFFERENT

\begin{tabular}{|c|c|c|c|c|c|}
\hline & \multicolumn{5}{|c|}{ BLOODS } \\
\hline & $\begin{array}{l}W B C \\
(100 / \mathrm{c} \mathrm{mm})\end{array}$ & $\begin{array}{l}R B C \\
(\mathrm{~m} / \mathrm{c} \mathrm{mm})\end{array}$ & $\begin{array}{l}H b \\
(g / \%)\end{array}$ & $\begin{array}{l}P C V \\
(\%)\end{array}$ & $\begin{array}{l}M C V \\
(c \mu)\end{array}$ \\
\hline $\begin{array}{l}\text { Manual } \\
\text { Coulter S } \\
\text { Ratio }\end{array}$ & $\begin{array}{r}862.7 \\
898.6 \\
0.96\end{array}$ & $\begin{array}{r}403 \cdot 55 \\
403 \cdot 82 \\
0.999\end{array}$ & $\begin{array}{r}1233 \cdot 5 \\
1225 \cdot 5 \\
1 \cdot 006\end{array}$ & $\begin{array}{r}3774.8 \\
3794 \cdot 8 \\
0.994\end{array}$ & $\begin{array}{l}947 \cdot 8 \\
942 \cdot 0 \\
1 \cdot 006\end{array}$ \\
\hline
\end{tabular}

over a period of four weeks during which time the calibration of the machine had not been altered.

\section{SUMMARY}

The Coulter counter model $\mathbf{S}$ has been tested. The reproducibility was determined by repeated counts on the same blood sample and the coefficient of variation of the haemoglobin, cell count, packed cell volume, mean corpuscular volume, mean corpuscular haemoglobin concentration, and mean corpuscular haemoglobin were found to be $10 \%$ or less. The coefficient of variation for the leucocyte count was less than $2.0 \%$. There was no significant difference in reproducibility if diluted blood samples (as would be obtained from capillary blood) or whole blood samples using dipotassium EDTA as the anticoagulani ( 1 to $2 \mathrm{mg}$ per $\mathrm{ml}$ ) were used.

All the results were found to be accurate provided that samples with leucocyte counts exceeding 20,000 per $\mathrm{c} \mathrm{mm}$ were excluded.

The effect of a preceding sample on the results of the sample being counted showed that the 'carryover' 

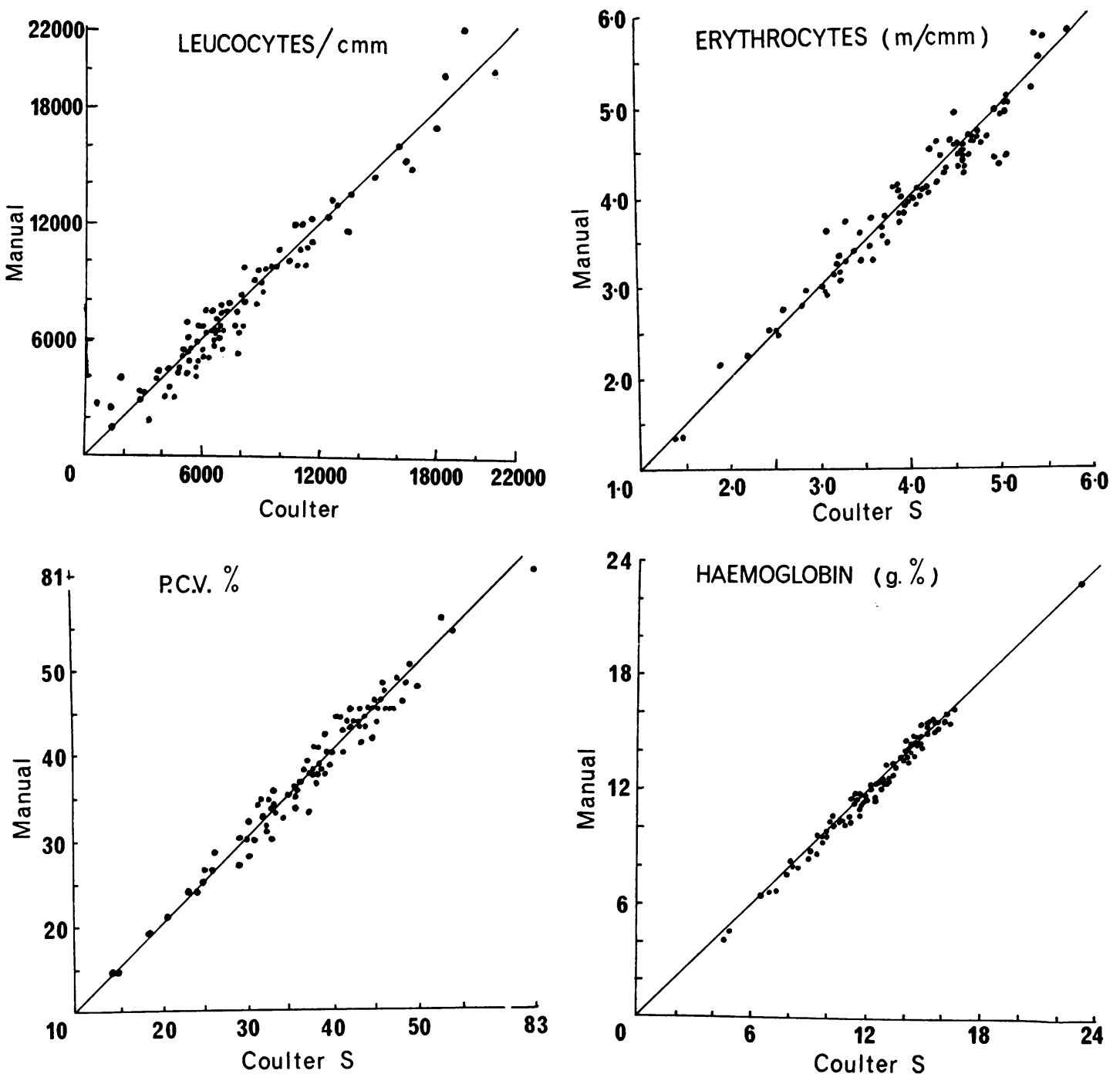

FIG. 12. The results of haemoglobin, red cell, white cell, and packed cell volume determinations by manual methods and the Coulter model $S$ on 100 different blood samples from patients with various blood disorders.

was between 2 and $3 \%$, causing significant errors in the leucocyte count only in samples following bloods with very high leucocyte counts.

The cost of operating was approximately 5.77 pence for materials only when using buffered saline and lysing agent purchased from the manufacturers.

Variations in mains voltage between 180 and 260 volts did not affect the performance of the counter.
The machine, once calibrated, did not drift or alter over a period of eight weeks. It is easy to use, capable of producing results at the rate of 150 to 180 per hour and has operated reliably over a period of three months, during which there were few breakdowns and those were speedily remedied either by the laboratory staff or by the manufacturers. On only one occasion was the counter out of action for 24 hours. 